\title{
Contribution of coupling elements to the seismic demand of walls in reinforced concrete buildings
}

\author{
Lilibeth Ramos $^{\mathrm{a} *}$ (D), Matías Hube ${ }^{\mathrm{a}, \mathrm{b}}$ (D) \\ a Pontificia Universidad Católica de Chile, Av. Vicuña Mackenna, Santiago 7820436, Chile. E-mail: Iramos1@uc.cl, mhube@ing.puc.cl \\ b Centro de Investigación para la Gestión Integrada del Riesgo de Desastres (CIGIDEN), ANID/FONDAP/15110017, Av. Vicuña Mackenna, \\ Santiago 7820436, Chile \\ * Corresponding author
}

http://dx.doi.org/10.1590/1679-78255931

\begin{abstract}
Architectural configurations of reinforced concrete $(\mathrm{RC})$ wall buildings force the connection of structural walls with beams, slabs and adjacent walls to distribute habitational spaces, generating interaction between those structural elements that results in a coupled structural system. Studies on resisting planes of RC buildings damaged during 2010 Chile earthquake suggest that the behavior of structural walls was highly influenced by the interaction of the resisting plane with the rest of the structure. Furthermore, researchers have identified 7the high levels of axial load as one of the principal causes of the observed wall damage on these buildings, and that a significant amount of this load comes from the seismic demands. However, there is uncertainty about how different coupling elements contribute to the seismic demands in RC walls. In this work, the seismic demands of axial load, shear and moment of RC walls are estimated from three buildings damaged during the 2010 earthquake using detailed finite element models that consider their three-dimensional layout. the contribution of coupling elements to the seismic demands of the studied RC walls is determined. Additionally, the effects of the assumed stiffness of structural elements over the seismic demands is evaluated. The results show that slabs have the largest contribution to the seismic axial load in walls, contributing with more that $90 \%$, followed by adjacent walls and connecting beams. Furthermore, the obtained moment and shear diagrams of the studied walls are significantly different than those of cantilever walls, and it was found that the assumed stiffness of structural elements exerts an important effect on the prediction of the seismic demands in RC walls.
\end{abstract}

\section{Keywords}

reinforced concrete; walls; coupled walls; building; axial load; seismic demands.

\section{Graphical Abstract}
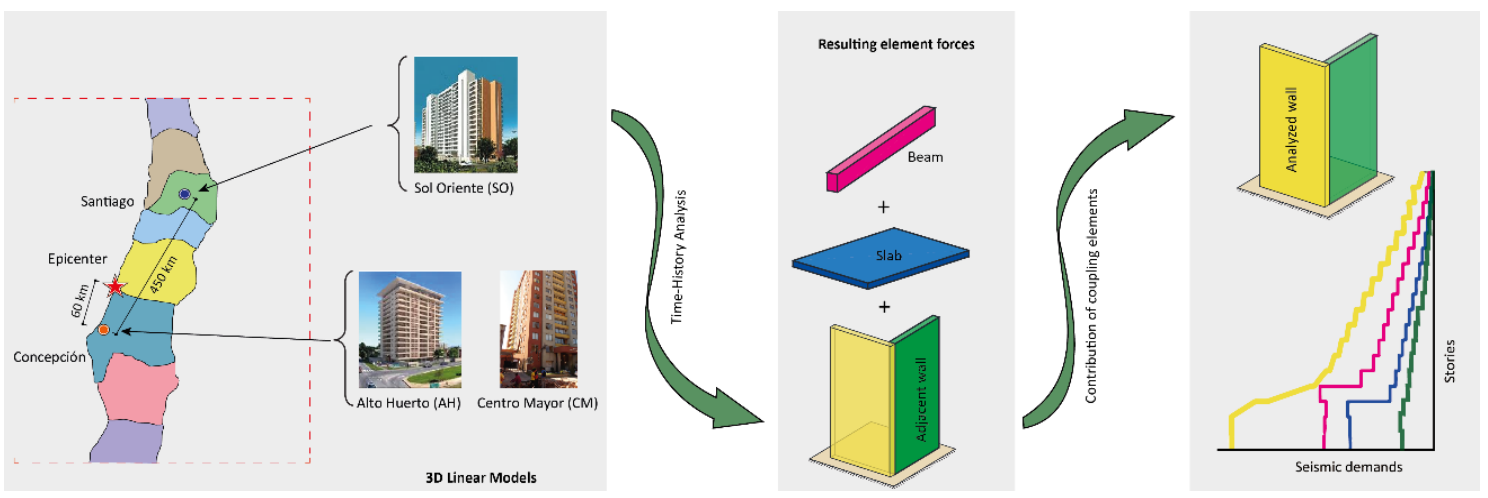

Received: January 11, 2020. In revised form: January 17, 2020. Accepted: February 10, 2020. Available online: March 10, 2020. https://doi.org/10.1590/1679-78255931

Latin American Journal of Solids and Structures. ISSN 1679-7825. Copyright (c) 2020. This is an Open Access article distributed under the terms of the Creative Commons Attribution License, which permits unrestricted use, distribution, and reproduction in any medium, provided the original work is properly cited. 


\section{INTRODUCTION}

Reinforced concrete (RC) structural wall buildings are widely used in the world due to their capacity to withstand seismic loads, to control lateral displacements and limit damage on nonstructural components. Typically, the architectural configurations of these buildings force the connection of structural walls with beams, slabs and adjacent walls to distribute habitational spaces. Hence, an interaction between the structural elements occurs and the buildings become coupled systems, which must be studied considering a three-dimensional behavior. Indeed, a recent study by Alarcón et al. (2015) on resisting planes of RC buildings damaged during 2010 in Chile suggests that the behavior of structural walls was highly influenced by the interaction of the resisting plane with the rest of the structure. Furthermore, experimental studies have shown that building responses are influenced by wall coupling due to slabs and beams (Bertero et al., 1985) and that the three-dimensional interaction between walls and slabs increases the overturning moment capacity (Panagiotou et al., 2011), and the shear demand in walls (Panagiotou et al., 2011; Panagiotou et al., 2009).

Several research efforts have been conducted to assess the behavior of RC coupled walls. These studies have contributed to identifying optimal geometrical configurations for coupled walls (Harries et al., 2004), as well as identifying their failure mechanism by using real scale models (Lehman et al., 2013). A pre-design method has also been proposed (Aksogan et al., 2014), and a comparison between the force and displacement methods for designing coupled walls has been performed (Fox et al., 2014a). Additionally, three different methods for the capacity design of coupled walls were compared by Fox et al. (2014b) and an analytical model that accounts for element coupling was proposed by Lu and Panagiotou (2016). Furthermore, procedures for estimating the inelastic response of higher modes for coupled walls were proposed by Pennucci et al. (2015) and for estimating the seismic shear demand of walls buildings were developed by Pugh et al. (2017). Finally, a shake table tests of a five-story coupled wall (Fischinger et al., 2017), representative of an apartment building in central Europe, showed that coupled beams induced axial loads in the walls, which contributed to the sudden shear failure observed in the test.

Studies about the behavior of RC structural walls during the 2010 Chile earthquake (Wallace et al., 2012; Westenenk et al., 2012; Westenenk et al., 2013; Jünemann et al.,2016) concluded that buildings remained essentially elastic until an abrupt brittle failure occurred in some cases. Additionally, other research (Wallace et al., 2012; Jünemann et al., 2015; Alarcón et al., 2014) has identified the high levels of axial load as one of the principal causes of the observed wall damage on these buildings. Hence, to further understand the behavior of RC walls it is critical to properly estimate the seismic axial loads, and identify how through the three-dimensional interaction, the different coupling elements contribute to the seismic demands in such walls.

The first objective of this paper is to quantify the contribution of coupling elements to the seismic demands of axial load, shear and moment along walls height in RC buildings. The second objective is to analyze the effects of using different modeling assumptions on the predicted seismic demands in these walls.

To achieve the first goal, three buildings damaged during the 2010 Chile earthquake are used to assess the seismic demand in RC walls. The buildings are analyzed considering their three-dimensional layout using detailed elastic finite element models in ETABS (2010). Since yielding of elements is expected before the buildings reach their strength in Englekirk (2003), the reduction factors for the moments of inertia proposed by the ACl 318-14 (ACl, 2014) are used for columns, beams, walls, and slabs. These factors account for the cracking and inelastic action near or beyond the yield level and have shown to produce reasonable correlation with both experimental and analytical results (Moehle, 1992; Lepage, 1998). The seismic demands are estimated through response history analyses using a set of six Chilean seismic records from the 2010 earthquake, applying the ground motions in both horizontal directions simultaneously. From these analyses, an estimation of the height-wise contributions of coupling elements to the seismic axial load, shear and moment in eight damaged walls is obtained, identifying the participation of slabs, beams, and adjacent walls.

To investigate the effects of using different modeling assumptions on the seismic demands of the selected walls, three additional models were created and subjected to the same ground motions as the base model. The first one uses the $\mathrm{ACl}$ 318-14 (ACl, 2014) reduction factors for beams, columns, and walls, but a larger factor for slabs. For the second model, gross section properties are considered for the structural elements. Finally, the third additional model is identical to the second one, but it considers a diaphragm with infinite in-plane stiffness, as commonly assumed in engineering practice.

\section{BUILDING DESCRIPTION}

Three residential buildings damaged during the 2010 Chile earthquake are considered for this study. The three buildings were designed using the Chilean seismic codes in force at the time of the 2010 earthquake NCh430 and NCh433 [INN, 1996; INN, 2008), which incorporaded ACl 318-95 (ACl, 1995) seismic provitions except the special boundary 
elements. Two of these buildings ( $\mathrm{CM}$ and $\mathrm{AH}$ ) are located in Concepción and the third one (SO) in Santiago. Concepción was the city most affected by the earthquake and it is located about $60 \mathrm{~km}$ southeast of the hypocenter (Boroschek et al., 2012). Santiago is located at about $450 \mathrm{~km}$ north from Concepción (see Figure 1). These buildings experienced moderate to severe damaged, mostly concentrated in RC walls of the basements and the first floor. After the earthquake, the CM building was demolished and, the buildings $\mathrm{AH}$ and SO were repaired, and they remain operational thus far.

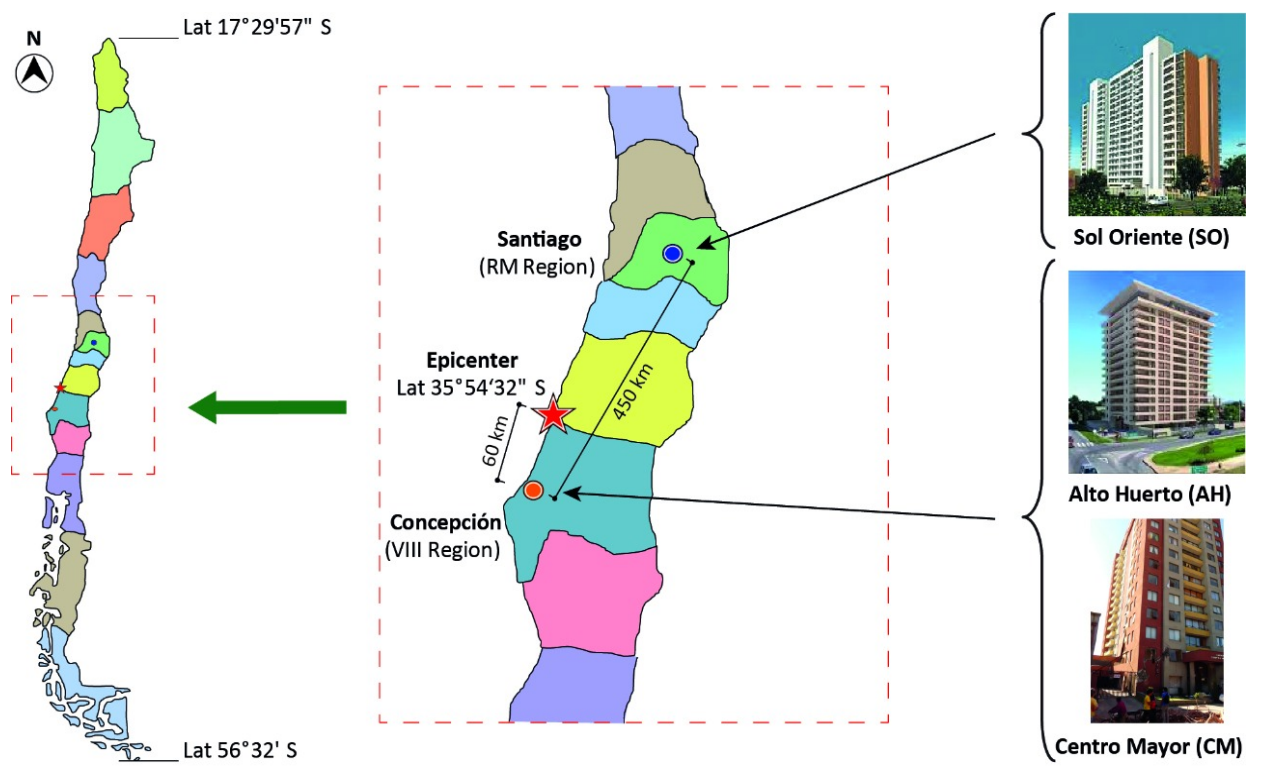

Figure 12010 Chile earthquake hypocenter and location of Santiago and Concepcoón cities.

General characteristics of the three buildings are summarized in Table 1. The table includes information about the city, the number of stories (above grade and below grade), built year, floor plan area (including basements' area), and the soil type used for designing the buildings according to the Chilean code (INN, 1996). Soil type II represents dense gravel or clay with shear wave velocity larger than $400 \mathrm{~m} / \mathrm{s}$ in the upper $10 \mathrm{~m}$, and soil type III represents gravel or clay with shear wave velocity lower than $400 \mathrm{~m} / \mathrm{s}$ (INN, 1996). A listed in Table 1 is the effective acceleration according to NCh 433 (INN, 1996) which may be interpreted as the peak ground acceleration and T is the fundamental period of the building. The fundamental period was estimated from finite element models of the buildings considering cracked sections following $\mathrm{ACl}$ 318-14 ( $\mathrm{ACl}, 2014)$. The finite element models are described later.

Table 1 General characteristics of RC buildings considered in this study.

\begin{tabular}{cccccccc}
\hline $\begin{array}{c}\text { ID } \\
\text { building }\end{array}$ & City & \# Stories & Built year & $\begin{array}{c}\text { Floor plan } \\
\text { area (m2) }\end{array}$ & Soil type & $\boldsymbol{A}_{\mathbf{0}}(\mathbf{g})$ & $\boldsymbol{T}(\mathbf{s})$ \\
\hline CM & Concepción & $18+1$ & 2005 & 13,870 & III & 0.4 & 1.242 \\
AH & Concepción & $15+2$ & 2009 & 12,665 & III & 0.4 & 0.922 \\
SO & Santiago & $18+2$ & 2007 & 10,190 & II & 0.3 & 1.332 \\
\hline
\end{tabular}

The three considered buildings have a typical story with a relatively rectangular plan layout (Figure 2). The buildings' structural system is comprised mainly by RC structural walls to withstand gravity and lateral loads. They are characterized of a typical floor plan with a central longitudinal corridor with walls, and transverse walls that separate building apartments and interior rooms. Transverse walls run from the corridor toward the building exterior creating a topology referred to as "fishbone" (Jünemann et al., 2015) (Figure 2). Most of these walls have a thickness of $20 \mathrm{~cm}$ and non-rectangular cross-sections. The damaged walls analyzed in this study are highlighted in red in Figure 2 . These walls were selected because they suffered damage during the 2010 Chile earthquake. The CM building has 18 stories and 1 basement, with commercial spaces in the first level. It has slabs $15 \mathrm{~cm}$ thick and inverted deep beams $20 \mathrm{~cm}$ wide, and between 50 to $150 \mathrm{~cm}$ depth. The AH building has 15 stories and 2 basements, with slabs of 15 and $20 \mathrm{~cm}$ thick, respectively. Beams sections have widths of 20,30 and $40 \mathrm{~cm}$, and depths that range from 35 to $150 \mathrm{~cm}$. The SO building has 18 stories and 2 basements, and it is composed by two symmetrical rectangular blocks separated by a construction 
joint (Figure 2c shows one of these blocks). This latter building has few deep beams of 20 by $75 \mathrm{~cm}$ and slabs of $15 \mathrm{~cm}$ thick. More information about these buildings is available elsewhere (Westenenk et al., 2012; Westenenk et al., 2013; Jünemann et al., 2016).

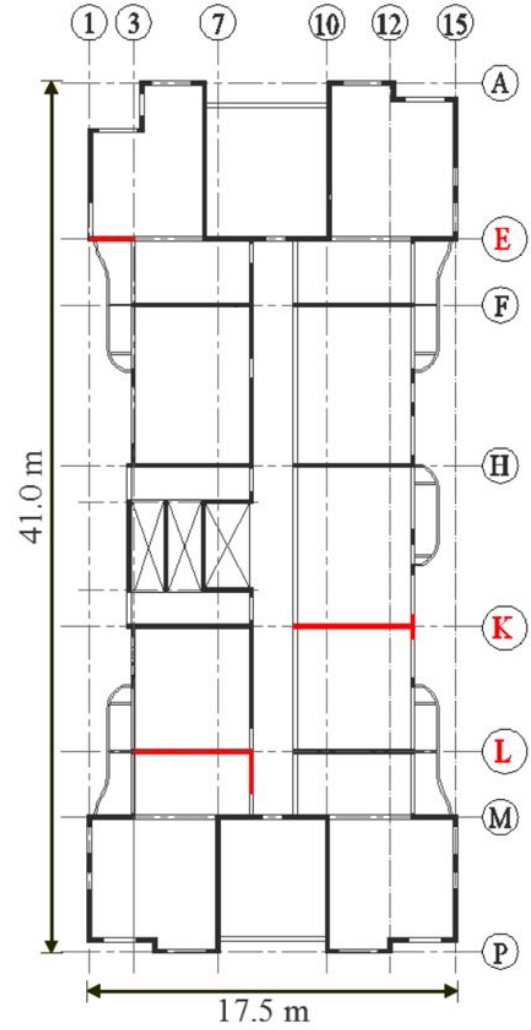

a)

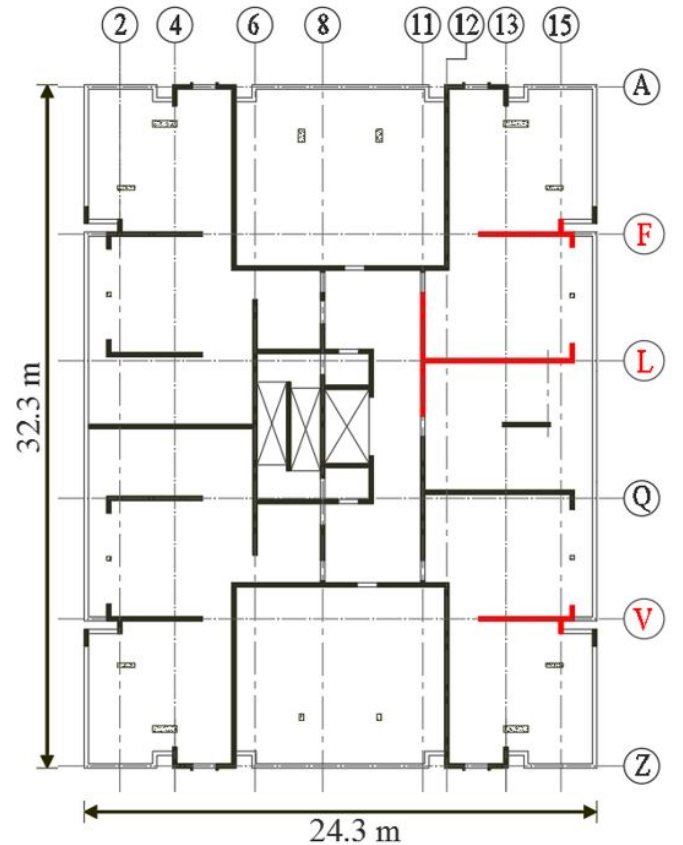

b)

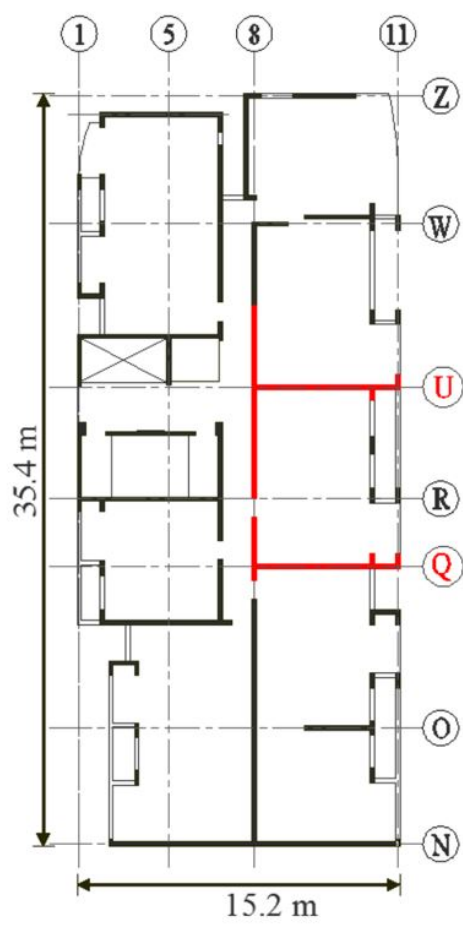

c)

Figure 2 Plan view of the typical story of considered buildings: a) CM; b) AH; c) SO. Damaged walls analized in this study are shown in red.

\section{FINITE ELEMENTS MODELS AND GROUND MOTIONS}

The elastic seismic response of the described buildings was obtained using finite element models developed in ETABS (2010) (Figure 3). Walls and slabs were modeled using 4-node shell elements with a thin plate formulation which neglects transverse shear deformation (Habibullah, 1992). Beams were modeled as frame elements and the soil-structure interaction was not accounted for. Fixed supports were considered in the base, and the seismic mass was calculated from the dead load and $25 \%$ of the live load. The diaphragms were modeled considering flexural and in-plane stiffness, which are referred to as semi-rigid in ETABS (2010). The used finite element models correspond to the actual ones used for the structural design of the buildings. The elements cross-sections and materials properties were not modified. 




a)



b)

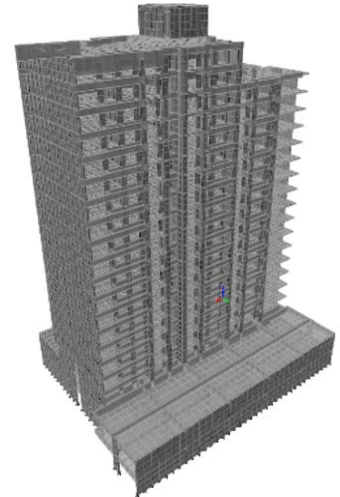

c)

Figure 3 3D views of the finite element models: a) CM building; b) AH building; c) SO building.

Reduced moments of inertia as proposed by $\mathrm{ACl} 318-14(\mathrm{ACl}, 2014)$ for factored load analysis were used in each model. Those reduced moments of inertia are aimed to reflect the degree of cracking and the inelastic action of the structural members near or beyond yielding. For beams, columns, and slabs, a moment of inertia of $0.35 \mathrm{lg}$, $0.7 \mathrm{lg}$, and $0.25 \mathrm{lg}$ was used, respectively, were $\mathrm{lg}$ is the gross moment of inertia. The walls' moment of inertia was modeled as $0.5 \mathrm{lg}$, which is an intermediate value between the range of $0.35 \mathrm{lg}$ and $0.7 \mathrm{lg}$ proposed by the $\mathrm{ACl} 318-14(\mathrm{ACl}, 2014)$. Reduced shear and axial stiffness were not considered for walls as they are not prescribed in the ACl 318-14 (ACl, 2014). The buildings' fundamental periods calculated with the described assumptions were previously summarized in Table 1.

\subsection{Ground Motions}

Response history analyses were conducted using ground motions from the available records of the 2010 Chile earthquake and selected based on buildings' location. Buildings located in Concepcion (CM and $\mathrm{AH}$ ) were subjected to seismic records from the San Pedro (SP), Constitución (CT) and Concepcion (CO) stations (CSN, 2019; ONEMI, 2019). The seismic records Santiago Centro (SC), Santiago Peñalolén (SN) and Santiago Puente Alto (SPA) (ONEMI, 2019) were used for the SO building located in Santiago. The pseudo-acceleration and displacement response spectrum of the two horizontal components (EW, NS) of the six considered ground motions are shown in Figure 4.



a)

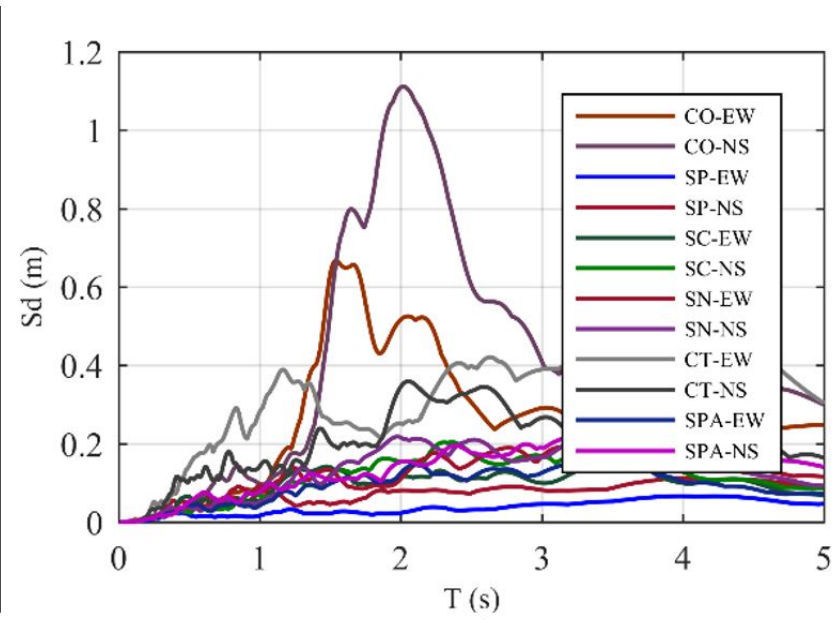

b)

Figure 4 a) Pseudo-acceleration and b) displacement response spectrum for selected ground motions (5\% damping ratio).

For conducting the response history analyses, both horizontal components of the seismic records were applied simultaneously to the building considering two possible orientation of the ground shaking (i.e. aligning the NS component of a ground motion with the longitudinal direction of the buildings, or with the transverse direction of the buildings). To obtain comparable responses between ground motions, seismic records were scaled to a spectral displacement (Sd) of $10 \mathrm{~cm}$ at the fundamental period of the buildings. This spectral displacement is about the design displacement according to the current Chilean code (MINVU, 2011) at the average period of the three buildings, for a site characterized 
by medium stiff soil, and an effective acceleration of $0.3 \mathrm{~g}(\mathrm{Sd}=10.73 \mathrm{~cm}$ for an average period of $1.17 \mathrm{~s})$. The horizontal component applied in the transverse direction of the buildings (i.e. direction of the damaged walls) was considered for obtaining the scaling factor of the records and was applied to both horizontal components. The spectral displacement at the fundamental period of each building, and the scaling factors used for each horizontal component of the ground motions are summarized in Table 2 for buildings located in Concepción and in Table 3 for the located in Santiago. The tables also show the peak ground acceleration (PGA) of each component of the seismic records.

Table 2 PGAs of the ground motions, spectral displacements at the fundamental period of the buildings CM and AH located in Concepcion and used scaling factors.

\begin{tabular}{|c|c|c|c|c|c|}
\hline \multirow{2}{*}{ Ground motions } & \multirow{2}{*}{$\frac{\text { PGAs }}{\text { (g) }}$} & \multicolumn{2}{|c|}{$\mathrm{Sd}(\mathrm{cm})$} & \multicolumn{2}{|c|}{ Scaling factors } \\
\hline & & CM & $\mathbf{A H}$ & $\mathrm{CM}$ & $\mathbf{A H}$ \\
\hline CO_EW & 0.29 & 21.21 & 8.30 & 0.47 & 1.21 \\
\hline CO_NS & 0.40 & 17.67 & 11.19 & 0.57 & 0.89 \\
\hline SP_EW & 0.58 & 3.10 & 1.37 & 3.22 & 7.29 \\
\hline SP_NS & 0.61 & 4.33 & 5.46 & 2.31 & 1.83 \\
\hline CT_EW & 0.63 & 35.65 & 13.69 & 0.28 & 0.73 \\
\hline CT_NS & 0.54 & 15.58 & 22.58 & 0.64 & 0.44 \\
\hline
\end{tabular}

Table 3 PGAs of the ground motions, spectral displacements at the fundamental period of the SO building located in Santiago and used scaling factors.

\begin{tabular}{cccc}
\hline \multirow{2}{*}{ Ground motions } & PGAs & Sd & Scaling \\
\cline { 2 - 4 } & (g) & (cm) & factors \\
\hline SC_EW & 0.31 & 13.14 & 0.76 \\
SC_NS & 0.21 & 9.38 & 1.07 \\
SN_EW & 0.29 & 10.80 & 0.93 \\
SN_NS & 0.30 & 13.52 & 0.74 \\
SPA_EW & 0.27 & 9.40 & 1.06 \\
SPA_NS & 0.27 & 11.74 & 0.83 \\
\hline
\end{tabular}

\section{SEISMIC DEMAND ON WALLS AND CONTRIBUTION OF COUPLING ELEMENTS}

One damaged wall of each building was selected and detailed results of them are presented in this section: wall in axis $\mathrm{E}$ in $\mathrm{CM}$ building (E-CM), wall in axis $\mathrm{V}$ in $\mathrm{AH}$ building ( $\mathrm{V}-\mathrm{AH})$, and wall in axis $\mathrm{U}$ in SO building (U-SO) (Figure 2). The three studied walls have $20 \mathrm{~cm}$ thickness and the are highlighted in the elevations of Figure 5 . Additionally, Figure 5 shows the variation of the cross sections of the studied walls along the height of the buildings. The beams conected to the walls are shown in blue and the dimensions of their cross-sections are specified. Figure 5 clearly shows the complexity of the layout of actual walls in RC buildings.

The wall E-CM (Figure 5a) has a rectangular cross-section along its height and it is not connected to adjacent walls. The numbers of beams connected to this wall vary along the wall height, as well as the beams dimensions. The wall $\mathrm{V}$-AH is a flag-shaped wall as its cross-section length increases from the 2 nd story (Figure $5 \mathrm{~b}$ ). The cross-section of this wall is rectangular from the second basement to the 1st story, and it contains flanges from the second floor to the upper stories of the building. The number and cross sections of connecting beams varies along the wall height.

Finally, the wall U-SO is also a flag-shaped wall as its cross-section length increases from the 1st story (Figure 5c). For the 1st and 2 nd basement the wall has a T-shaped cross-section with a $25 \mathrm{~cm}$ thickness web and $20 \mathrm{~cm}$ thickness flange which changes to $20 \mathrm{~cm}$ in the upper stories. Given that, the wall's flange is connected to an adjacent wall in those stories (shown in green in Figure $5 \mathrm{c}$ ), the length of the flange was defined based on the effective flange width accordfing to the $\mathrm{ACl} 318-14(\mathrm{ACl}, 2014)$. Between the 1st and the 16th story the wall is also connected to and adjacent wall through the flange, which is in the opposite side as that of the basements stories. For U-SO wall, the number and cross section of connecting beams also varies along the wall height.

The showed and described wall cross-section were used to define the grups of shells to be considered as a unity for stimating the force elements in ETABS. Based on that, pier labels were assigned to each wall and the seismic demands of axial load $(P)$, shear $(V)$ and moment $(M)$ were obtained from the pier force output table. Results were obtained at the top and bottom locations of each story. The response values of $P, V$ and $M$ were analyzed at the instant of maximum and 
minimum roof displacements. These instants are considered because the $\mathrm{ACl} 318-14(\mathrm{ACl}, 2014)$ and the Chilean code (MINVU, 2011) use the roof displacement to determine whether special boundary elements are required in walls.

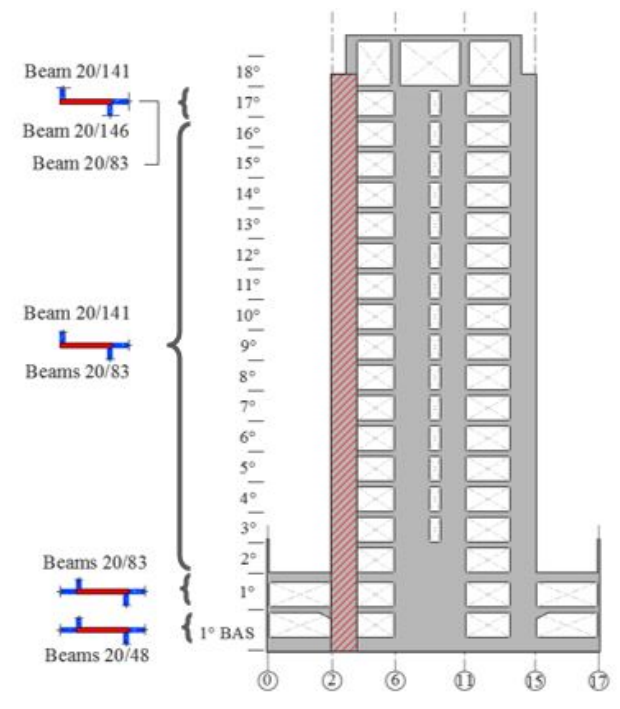

a)

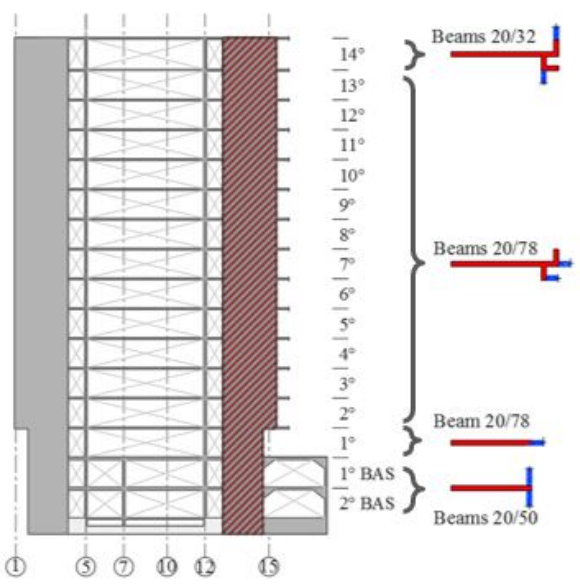

b)

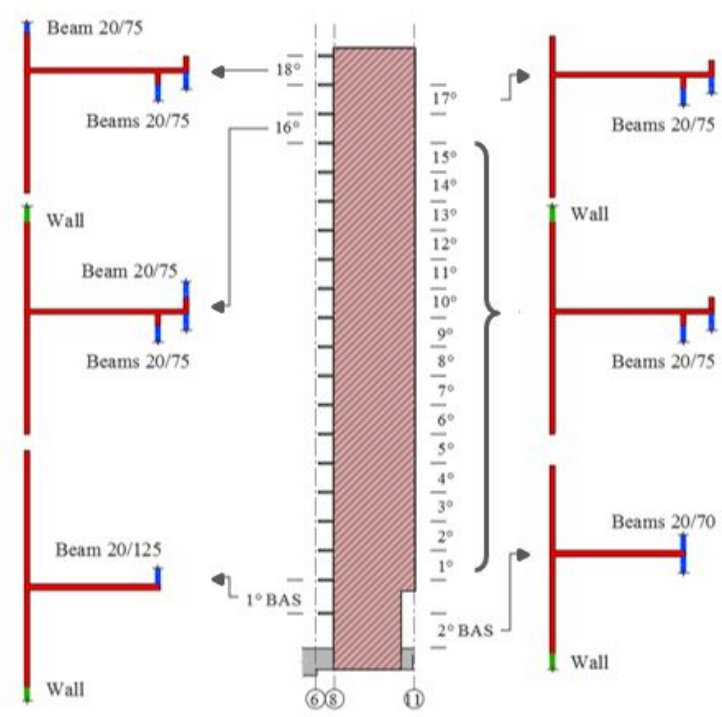

c)

Figure 5 Elevation view and cross sections of the studied walls: a) wall E-CM; b) wall V-AH; and c) wall U-SO.

To determine the contribution of the connected structural elements to the seismic demands of axial load, shear and moment along the studied walls it is necessary to process the resulting forces obtained from models. Figure 6a shows schematically a wall pier connected to slabs and beams at different stories. The axial load, shear and moment at the bottom of the pier at i-th story are $P_{w, i}^{B}, V_{w, i}^{B}$, and $M_{w, i}^{B}$, respectively (Figure $6 \mathrm{~b}$ ). The corresponding forces at the top of the pier at the same i-th story are $P_{w, i}^{T}, V_{w, i}^{T}$, and $M_{w, i}^{T}$.

The axial force, shear and moment at the bottom of a pier of the story i+1 are different than those at the top of the pier of the i-th story. This difference corresponds to the forces transferred from the slab and beams to the pier at this level. Therefore, the relationship of axial load, shear and moment between adjacent stories can be expressed as,

$P_{w, i}^{T}=P_{w, i+1}^{B}+P_{b, i}+P_{s, i}$

$V_{w, i}^{T}=V_{w, i+1}^{B}+V_{b, i}+V_{s, i}$ 
$M_{w, i}^{T}=M_{w, i+1}^{B}+M_{b, i}+M_{s, i}$

Where $P_{b, i}, V_{b, i}$ and $M_{b, i}$ are the axial load, shear and moment transferred by the beams of the story i (Figure 6a), respectively, and $P_{s, i}, V_{s, i}$ and $M_{s, i}$ are those transferred by the slab of the same story. The forces transferred by the beams are obtained from the output forces of the beam elements in ETABS (e.g shear in beams, which is the transferred as axial load to the pier). Finally, the contribution of the slabs to the seismic demands, is obtained by solving equations (1), (2) and (3) for $P_{s, i}, V_{s, i}$ and $M_{s, i}$, respectively.

The axial load and shear at the top and bottom of a pier of the $i$-th story are identical when the pier is not connected to an adjacent wall, and the moment varies along the pier height because of the shear. Therefore, the shear generated by the beams and slab connected at the top of a pier generates moments at the bottom of the pier. These contributions were considered in this study.

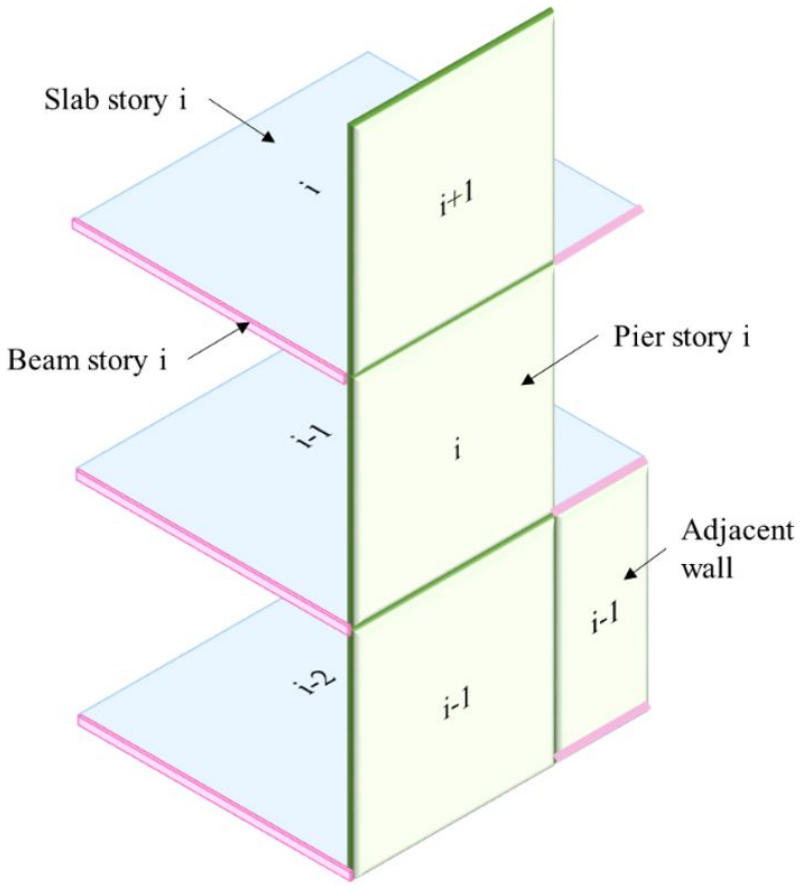

a)

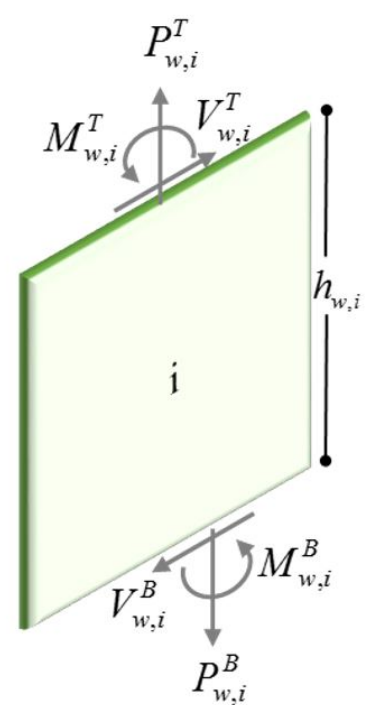

b)

Figure 6 Representative a) three-dimensional layout of a wall pier connected to slabs and beams and b) pier forces at the i-th story.

When a pier is connected to an adjacent wall (e.g. wall of story i-1 in Figure 6a), the axial load and shear at the top and bottom of the pier of the i-th story are different.

$P_{a, i}=P_{w, i}^{B}-P_{w, i}^{T}$

$V_{a, i}=V_{w, i}^{B}-V_{w, i}^{T}$

The differences $P_{a, i}$ and $V_{a, i}$ correspond to the contribution of the adjacent wall to the axial load and shear to the pier at this story, respectively. Finally, to obtain the contribution of the adjacent wall to the moment $\left(M_{a, i}\right)$ of the pier, the moment generated by shear of the beams and slab needs to be subtracted as follows, where $h_{w, i}$ is the height of the pier at the i-th story.

$M_{a, i}=M_{w, i}^{B}-M_{w, i}^{T}-\left(V_{b, i}+V_{s, i}\right) \cdot h_{w, i}$

The contribution of the slabs, beams, and adjacent walls to the seismic demands of the studied walls obtained with the previously described procedure is shown in Figure 7. The total axial load, shear and moment demand of walls E-CM, $\mathrm{V}-\mathrm{AH}$ and U-SO, at the instant of maximum roof displacement are shown along the normalized buildings height. 
The results shown in Figure 7 correspond to the seismic case that induced a compressive axial load in the walls (i.e. negative axial load in this study). It means that for the CM building the response when the NS component of the SP seismic record was applied in the direction of the damaged walls is shown. For the AH building the shown responses correspond to those of the SP seismic record, when the EW component was appliend in the interest direction. For the SO building, the results correspond to those of the SC seismic record applied with the NS component in the direction of the damaged walls. The horizontal dashed line indicates the ground level (G.L.).
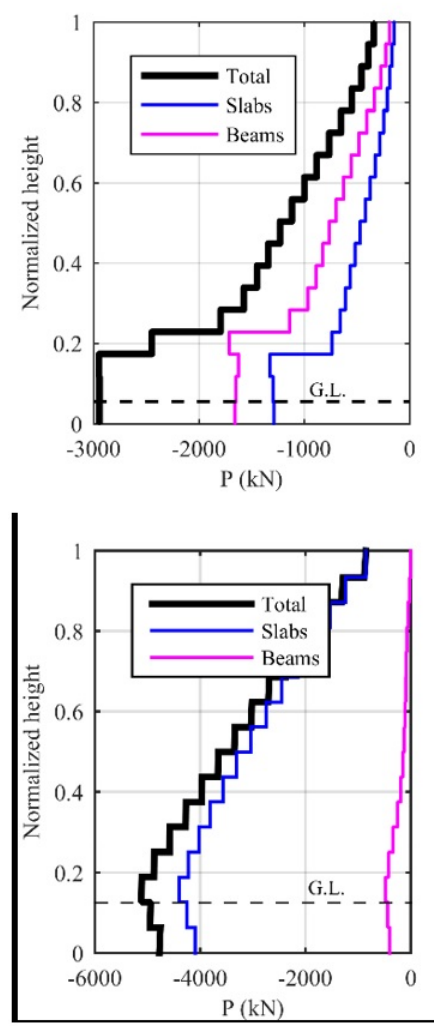

d) Axial load, V-AH



g) Axial load, U-SO

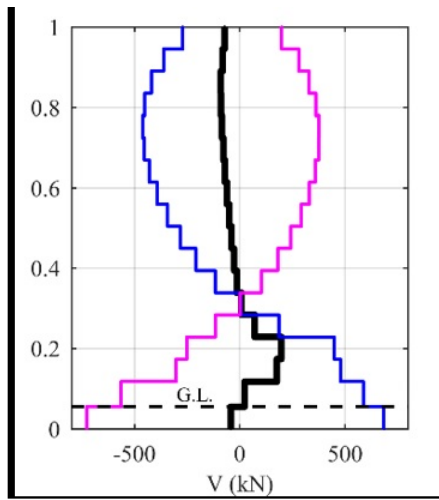

b) Shear, E-CM

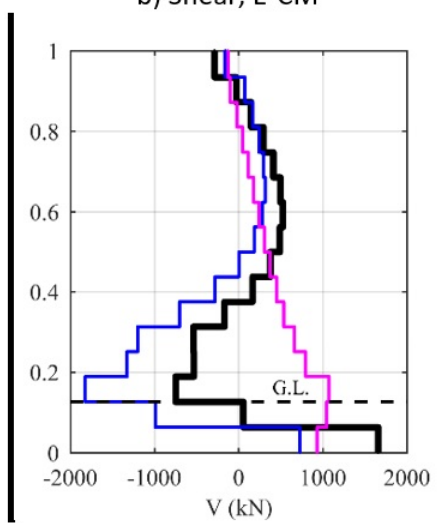

e) Shear, V-AH

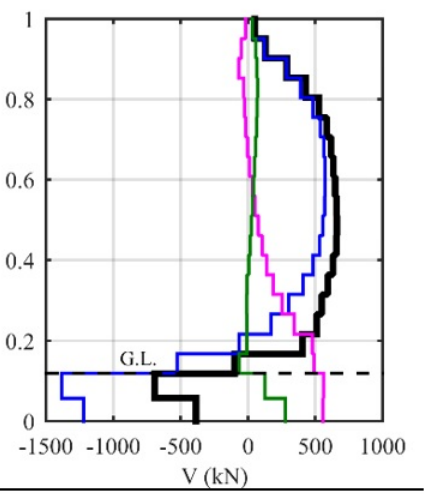

h) Shear, U-SO

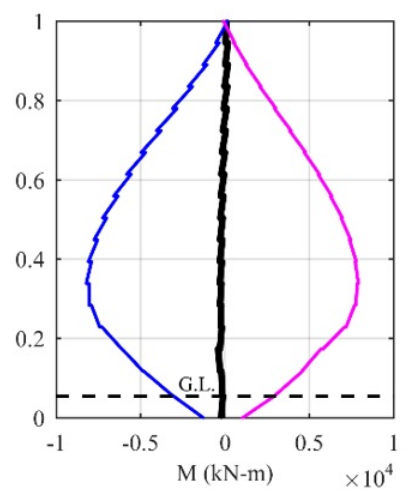

c) Moment, E-CM

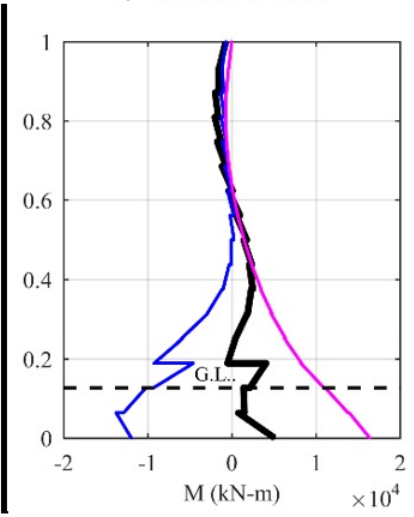

f) Moment, $\mathrm{V}-\mathrm{AH}$

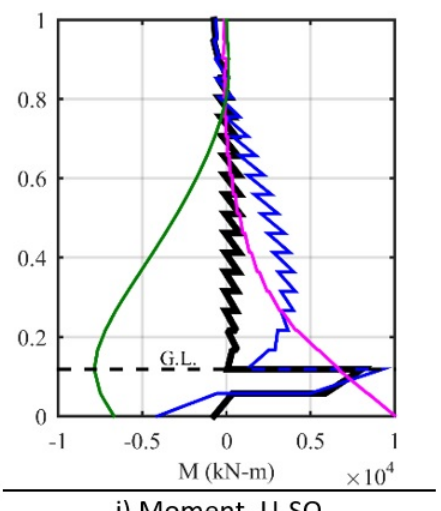

i) Moment, U-SO

Figure 7 Seismic contribution of coupling elements to: a) P of E-CM wall; b) V of E-CM wall; c) M of E-CM wall; d) P of V-AH wall; e) V of $\mathrm{V}-\mathrm{AH}$ wall; f) M of $\mathrm{V}-\mathrm{AH}$ wall; g) P of U-SO wall; h) V of U-SO wall and i) M of U-SO wall. (G.L. correspond to the ground level).

The maximum compressive seismic axial load predicted for the wall E-CM is 2,945 kN (total load in Figure 7a, which represents an axial load ratio $A L R=P / f_{c}^{\prime} A_{g}$ of 0.27 , where $f_{c}^{\prime}$ is the specified concrete compressive strength and $A_{g}$ is the gross cross-section of the wall. The maximum axial loads predicted for the walls $\mathrm{V}$-AH and U-SO are $5,119 \mathrm{kN}$ and $5,664 \mathrm{kN}$, that correspond to ALRs of 0.30 and 0.07 , respectively. These maximum values are predicted at the first story for the three walls, since the axial load decreases at the basements stories due to load transfer from the core walls to the basement perimeter walls. 
Regarding the contribution of slabs and beams to the seismic axial load demand in the wall E-CM, Figure 7a shows that the participation of beams (60\%) is larger than the participation of the slabs (40\%), and that these contributions are relatively uniform along the wall height. Beams of $141 \mathrm{~cm}$ and $83 \mathrm{~cm}$ depth are connected to wall E-CM from the $2^{\text {nd }}$ story to the top of the wall (Figure 5a), which exert a significant contribution to the axial load in this wall. Contrarily, most of the seismic axial load in wall V-AH is transferred through the slabs, which contribute on average $91 \%$ of the seismic axial load along the wall's height. It can be noted that beams connected to V-AH and U- SO walls are $75 \mathrm{~cm}$ and $78 \mathrm{~cm}$ depth. Finally, for wall U-SO, slabs and adjacent walls induce compressive forces, while beams exerting tension forces. The contribution of the beams is similar than that of the adjacent walls, generating that the total compressive seismic axial load in wall U-SO shows a similar behavior to that of the the axial load transferred solely by the slabs.

The contribution of slabs, beams and adjacent walls to the seismic axial loads of the studied walls (Figure 7) is highly influence by the location of such walls within the floor plan of the buildings. For the E-CM wall, conected beams of significant dimensions are also connected to nearby walls, and as expected, the beam in the elevation of the wall (axis $E$ ) is the one that contribute the most. In consequence, the contribution of beams to the seismic axial load of wall E-CM is larger than the contribution of slabs (Figure 7a). For wall V-AH, the connected beams (Figure 5b) correspond to exterior beams that acting mainly as gravitational beams and do not carry significant seismic forces. Therefore, the short distance between $\mathrm{V}$-AH wall and the long transverse wall in axis 12 (Figure 2b) induces shear forces in the slabs, which generates the largest contribution of these element to the wall. Finally, the opposite axial loads induced by beams and adjacent walls in wall U-SO are explained by the opposite locations of the beams and adjacent walls with respect to the web of this wall.

Regarding the shear demand, Figure 7 shows that the sign of the total shears changes at ground level for the three walls. This change is attributed to the back-stay effect induced by the basement stories (Moehle, 2015). Additionally, walls E-CM and $\mathrm{V}-\mathrm{AH}$ show an additional sign change of the shear at a normalized height of 0.28 and 0.38 , respectively. For the three walls, the maximum shears are located at the bottom of the walls around of $20 \%$ heigh, but they occur in different stories. For the wall E-CM, the maximum shear of $198 \mathrm{kN}$ occurs at the third story and is equivalent to a shear stress coefficient $\tau=0.09$. Where $\tau=V /\left(\sqrt{f_{c}^{\prime}} A_{v}\right), A_{v}$ is the effective shear area of the wall in $\mathrm{mm}^{2}$ and $f_{c}^{\prime}$ is in MPa. For the walls $\mathrm{V}-\mathrm{AH}$ and U-SO, a maximum shear of $1,659 \mathrm{kN}(\tau=0.29)$ and $885 \mathrm{kN}(\tau=0.13)$ are predicted at the second basement and first basement, respectively.

Figure 7 shows that the total shear demand in walls V-AH and U-SO is mostly attributed to the contribution of slabs. For such walls, the beams help to reduce the total shear demand in the lower stories. For wall E-CM, coupling beams and slabs exert opposite contributions of similar magnitudes to the shear (Figure 6b), which results in a reduced total shear along the wall height. Finally, Figure 7 shows that the contribution of the slabs to the total shear at the basement stories is significant in walls $\mathrm{V}-\mathrm{AH}$ and U-SO because the slabs transfer significant shear forces to the perimeter walls.

Regarding the moment demand, Figure $7 \mathrm{c}$ shows that in the E-CM wall the total maximum moment $(-397 \mathrm{kN}-\mathrm{m})$ is negligible compared to the moments transferred by the beams and the slabs. For the wall V-AH (Figure $7 f$ ), a maximum moment of 5,091 kN-m occurs at the wall base, and two sign changes of the diagram are observed, at $23 \%$ and $60 \%$ of the wall height. Finally, for the wall U-SO, a maximum moment of $8,047 \mathrm{kN}-\mathrm{m}$ is predicted at the ground level and several sign changes are observed along the wall height.

The contribution of the coupling elements to the total seismic moment diagram for wall E-CM follows the same trend observed for the shear diagram, where beams and slabs exert opposite contributions of similar magnitudes. A similar behavior is observed for the moment diagram in wall $\mathrm{V}-\mathrm{AH}$. where beams and slabs exert opposite contributions in the lower stories. Finally, for the wall U-SO the beams and slabs exert a joint contribution that is similar and opposite to the contribution of the adjacent walls. This behavior is observed above the ground level, whereas in the first basement the moment transferred by the slab to the wall U-SO significantly increases.

The envelopes of the compressive seismic axial load demand of the three studied walls, for the three seismic records and the two possible orientations of the ground shaking are shown in Figure 8. An average axial load of 5,065 kN, 4,602 kN and 6,240 kN, are predicted in the first story for walls E-CM, V-AH and U-SO, respectively. These forces correspond to ALRs of $0.46,0.27$ and 0.07 , respectively and a largest ALR of 0.83 is predicted for wall E-CM. These large values demostrate that the interaction with the coupling elements generates significant seismic axial load demands in the studied RC walls. Moreover, even though the ground motions were scaled to the same spectral displacement, large variation of the seismic axial loads envelopes are predicted by different ground motions, where the coefficient of variation of the seismic ALRs at the first stories are $0.47,0.46$, and 0.33 for walls E-CM, V-AH, and U-SO, respectively. These large variations are influenced by the second component of the seismic records, since reduced variations of ALRs were obtained when analyzing the buildings with only one ground motion component applied. 


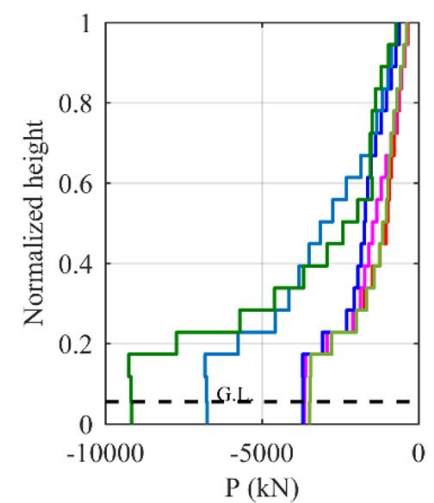

a)

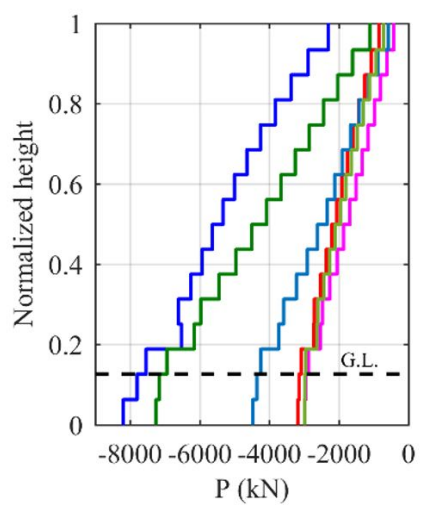

b)

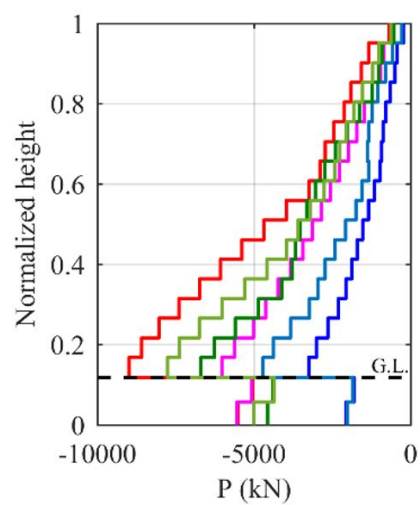

c)

Figure 8 Compressive axial load demand envelopes for the three seismic records and two possible orientations: a) wall E-CM; b) $\mathrm{V}-\mathrm{AH}$; and c) U-SO.

The envelopes of the shear demand are shown in Figure 9 in a similar way as the seismic axial load envelopes were shown. The shear envelopes for the different ground motions vary significantly along the height of the three walls and maximum values were predicted at different heights. Abrupt changes are observed at the first story and ground level due to the back-stay effect. Consequently, the estimation of the seismic shear demands for designing these coupled walls is complex, even when an elastic analysis is considered.

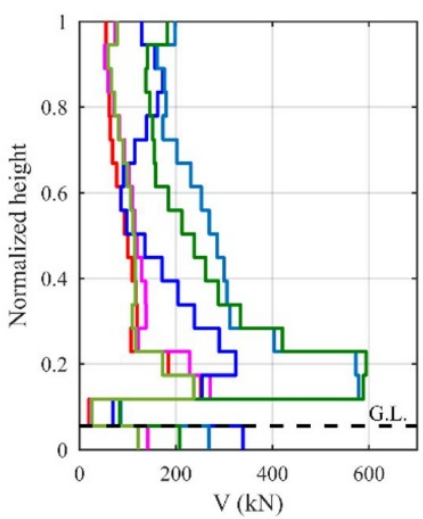

a)

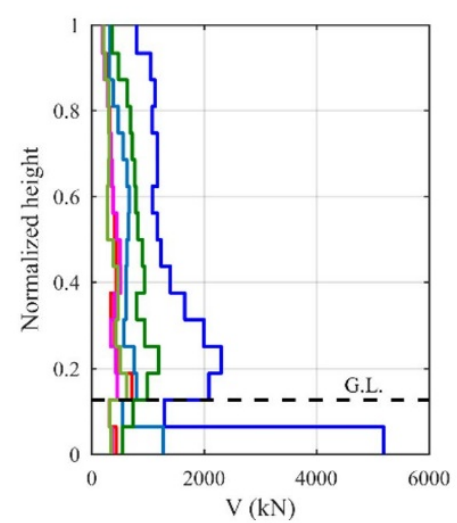

b)

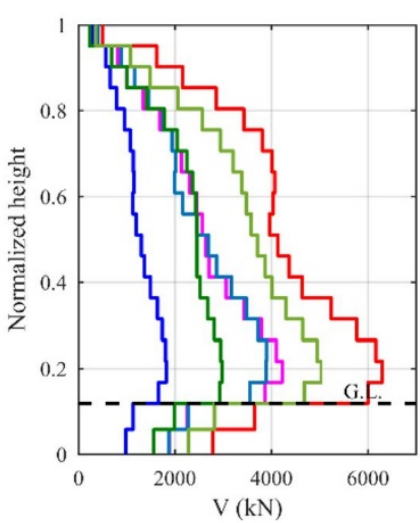

c)

Figure 9 Shear demand envelopes for the three seismic records and two possible orientations: a) wall E-CM; b) V-AH; and c) U-SO.

The envelopes of the moment demand of the three studied walls are shown in Figure 10, for the same ground motions considered in Figure 8 and Figure 9. Since the obtained moment diagrams envelopes were relatively symmetric for the three walls, Figure 10 shows only the envelope of the negative moments. The figure shows that the moment profiles of the studied walls have irregular shapes and are different than common profiles observed in cantilever walls (Pugh et al., 2017; Priestley and Amaris (2003); Panagiotou and Restrepo (2009)) and in walls coupled through beams studied by Paulay (1986). Additionally, Figure 10 shows that the maximum moment occurs at different heights and that abrupt changes in the moment diagram are observed for the three walls at the lower stories. 


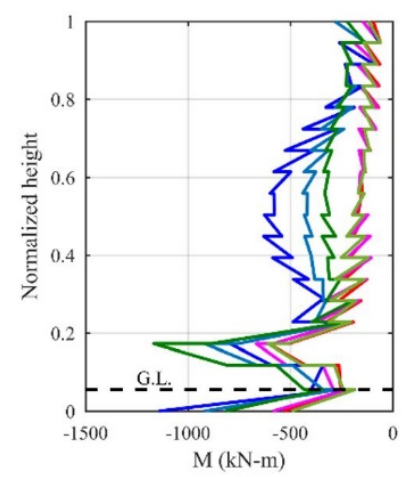

a)



b)



c)

Figure 10 Moment demand envelopes for the three seismic records and two possible orientations: a) wall E-CM; b) V-AH; and c) U-SO.

The contributions of coupling elements to the seismic axial load of the total of damaged walls highlighted in Figure 2 were also obtained, Figure 11 summarizes those contributions. The median contributions (in percentage) of slabs, beams and adjacent walls for the six ground motions at the instant of maximum roof displacement inducing compression and tension forces are shown with bars in Figure $11 \mathrm{a}$ and $11 \mathrm{~b}$, respectively. For walls in the AH and SO buildings, the slabs have the largest contribution to the seismic axial load for both compressive and tensile forces, with contributions that range between $90 \%$ and $160 \%$ according to the figure. The cases with contributions over $100 \%$ mean that beams exert an opposite effect. For these walls, the contribution of beams is relatively small and the contribution of adjacent walls for wall U-SO is larger for compressive forces (40\% contribution) than for tensile forces (-27\% contribution, i.e. the adjacent walls induces compressive forces when the wall is in tension). Figure 11 also shows that the contributions of coupling beams to the axial load demand in walls of CM building are larger than those in walls of AH and SO buildings. In particular, the beams contribution of $57 \%$ and $69 \%$ to the compressive axial loads of walls $\mathrm{E}-\mathrm{CM}$ and $\mathrm{K}-\mathrm{CM}$, respectively, exceeds the contributions from the slabs.

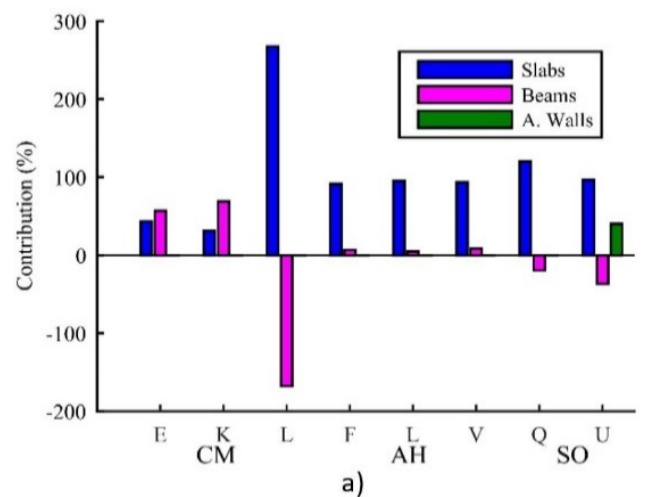

a)

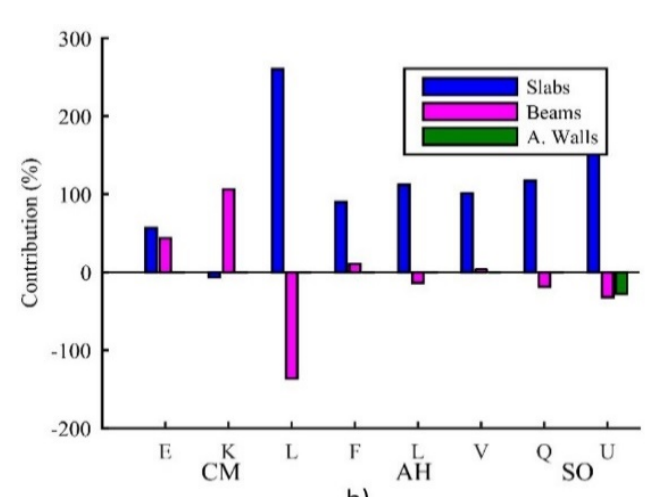

b)

Figure 11 Median contribution of coupling elements to the maximum axial load of walls at the first story for: a) compression and b) tension.

The ALRs at the first story of the previous eight walls, obtained from the compression and tension envelopes of the six seismic cases, are shown with a box plot in Figure 12a and Figure 12b, respectively (i.e. the compression ALRs in Figure 11a are shown as positive values). Significant seismic ALRs are predicted for the studied walls for both compression and tension cases. Additionally, large variation of the seismic ALR is predicted, with a minimum ratio of 0.02 for the wall Q-SO and a maximum ratio of 0.83 for the wall E-CM. The largest median ALR of 0.33 is obtained for wall E-CM for both compression and tension cases. For walls in the $\mathrm{AH}$ building ( $\mathrm{F}-\mathrm{AH}, \mathrm{L}-\mathrm{AH}$ and $\mathrm{V}-\mathrm{AH}$ ) the median ALRs for compression and tension cases are about 0.20, while for walls in the SO building (U-SO and Q-SO) these ratios are about 0.07 . 


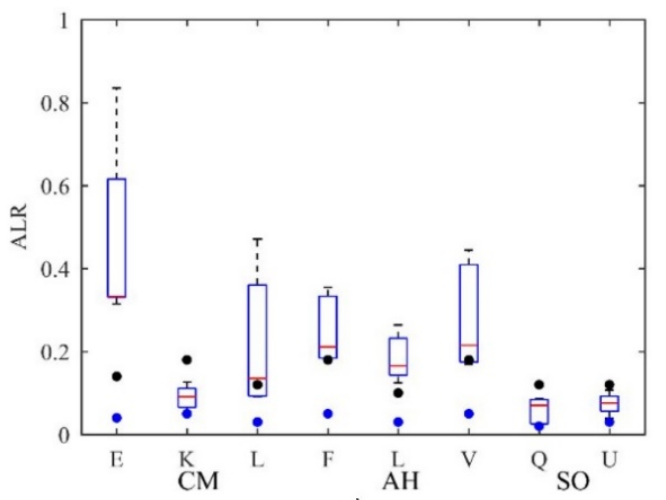

a)

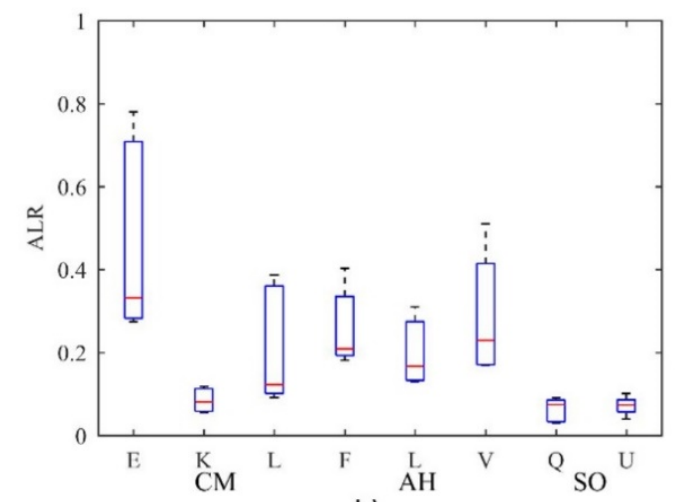

b)

Figure 12 ALRs in a) compression and b) tension of eight walls at the first story.

This Figure 12a also shows the ALRs of the selected walls for dead and live loads with black and blue dots, respectively. The ALRs for dead loads and live loads vary from 0.10 to 0.18 , and from 0.02 to 0.05 , respectively. By aaacomparing the dead ALRs with the seismic ALRs it is concluded that the median seismic ALRs are larger than the dead ALRs for five of the eight walls (Figure 12a). Additionally, the tensile seismic ALRs for these walls are larger than the gravitational (compressive) ALRs, which imply that tension forces are expected to develop at the first story of such walls.

\section{EFFECTS OF MODELING ASSUMPTIONS}

The results provided in the previous section were obtained with models wherein the reduced moment of inertia proposed by $\mathrm{ACl}$ 318-14 (ACl, 2014) were used. In order to assess the effect of the effective stiffness of the structural elements and the diaphragm flexibility, three additional modeling assumptions are considered for each building (Table 4). Model SR1 corresponds to the one used in previous sections (i.e. with semi-rigid diaphragm in ETABS and ACl effective stiffness of the elements). Model SR2 is similar to model SR1 but a larger moment of inertia for slabs was defined to simulate the behavior of less cracked slabs. Model SR3 is similar to model SR1 but considers the gross moment of inertia for all the structural elements. Finally, Model R3 is identical to model SR3, but considers a rigid diaphragm (i.e. infinite in-plane stiffness). This latter model is commonly observed in engineering practice in Chile and worldwide.

Table 4 Modelling assumptions considered for each building.

\begin{tabular}{|c|c|c|c|c|c|}
\hline \multirow{2}{*}{ Model } & \multirow{2}{*}{ Diaphragm } & \multicolumn{4}{|c|}{ Moment of Inertia } \\
\hline & & Beams & Columns & Walls & Slabs \\
\hline SR1 & Semi-rigid & $0.35 \lg$ & $0.70 \mathrm{lg}$ & $0.50 \mathrm{lg}$ & $0.25 \mathrm{lg}$ \\
\hline SR2 & Semi-rigid & $0.35 \mathrm{lg}$ & $0.70 \mathrm{lg}$ & $0.50 \mathrm{lg}$ & $0.40 \mathrm{lg}$ \\
\hline SR3 & Semi-rigid & $\lg$ & $\lg$ & $\lg$ & Ig \\
\hline R3 & Rigid & Ig & $\lg$ & $\lg$ & Ig \\
\hline
\end{tabular}

The fundamental periods of the analyzed buildings obtained with the four modelling assumptions are summarized in Table 5. The fundamental periods with less cracked slabs of models SR2 are on average 4\% smaller than those in models SR1. When gross sections are used for the structural elements (model SR3) the fundamental periods decrease by $33 \%$ compared to model SR1. Finally, if rigid diaphragm is also considered (model R3) the fundamental period decreases by $35 \%$ compared to model SR1, where periods obtained for the R3 models are equivalent to those obtained by previous studies (Westenenk et al., 2013; Jünemann et al., 2016). The in-plane stiffness of the diaphragm has a minimal effect in the fundamental period of the studied buildings since the periods of models R3 are about 3\% smaller than those of models SR3. The differences obtained in those later cases are smaller than those reported by Chacón et al. (2017) for free-plan RC buildings modeled with rigid or flexible diaphragms. 
Table 5 Fundamental periods of the three buildings with the four modelling assumptions.

\begin{tabular}{cccc}
\hline Model & & T (s) & SO \\
\cline { 2 - 4 } & CM & AH & 1.332 \\
SR1 & 1.242 & 0.922 & 1.274 \\
SR2 & 1.204 & 0.892 & 0.882 \\
SR3 & 0.834 & 0.628 & 0.865 \\
R3 & 0.814 & 0.603 & \\
\hline
\end{tabular}

The maximum roof displacement predicted for the three buildings, with the four modelling assumptions and the considered ground motions are shown in Table 6 . The median roof displacement of the four models for all buildings and all seismic cases is $13.7 \mathrm{~cm}, 1.4$ times larger than the considered spectral displacement. The comparison between the roof displacement obtained with model SR1 and SR2 shows that the predicted values using less cracked slabs (SR2 model) are on average $96 \%$ of the obtained with the SR1 model. When gross sections are considered (model R3 and SR3), the obtained roof displacements are $20 \%$ and $17 \%$ lower than the obtained with model SR 1 , respectively. Additionally, a comparison between model SR3 and R3 shows that the in-plane diaphragm stiffness has a negligible influence on the roof displacement, since values $4 \%$ larger are obtained from the SR3 model.

Table 6 Maximum roof displacement $(\mathrm{cm})$ predicted for each building.

\begin{tabular}{|c|c|c|c|c|c|c|c|c|}
\hline \multirow{2}{*}{ ID building } & \multirow{2}{*}{$\begin{array}{c}\text { Height } \\
\text { (cm) }\end{array}$} & \multirow{2}{*}{ Model } & \multicolumn{2}{|c|}{$\mathrm{CO}$} & \multicolumn{2}{|c|}{ SP } & \multicolumn{2}{|c|}{ CT } \\
\hline & & & E1 & E2 & E1 & E2 & E1 & E2 \\
\hline \multirow[t]{4}{*}{ CM } & 4,715 & SR1 & 15.14 & 15.02 & 16.88 & 17.50 & 16.39 & 15.80 \\
\hline & & SR2 & 14.58 & 13.68 & 19.45 & 16.92 & 13.65 & 16.52 \\
\hline & & SR3 & 12.11 & 5.57 & 22.23 & 8.43 & 16.38 & 12.18 \\
\hline & & R3 & 11.58 & 5.42 & 22.65 & 8.43 & 16.10 & 12.15 \\
\hline \multirow[t]{4}{*}{$\mathrm{AH}$} & 4,107 & SR1 & 14.83 & 14.43 & 15.03 & 15.12 & 24.48 & 9.29 \\
\hline & & SR2 & 14.88 & 15.67 & 14.62 & 14.79 & 23.19 & 8.46 \\
\hline & & $S R$ & 7.59 & 10.24 & 15.32 & 17.13 & 20.27 & 8.86 \\
\hline & & R3 & 7.16 & 9.00 & 15.9 & 15.12 & 18.51 & 8.69 \\
\hline \multirow[t]{5}{*}{ SO } & 5,064 & & \multicolumn{2}{|c|}{ SC } & \multicolumn{2}{|c|}{ SN } & \multicolumn{2}{|c|}{ SPA } \\
\hline & & SR1 & 16.39 & 15.52 & 2.40 & 6.07 & 15.28 & 13.76 \\
\hline & & SR2 & 16.57 & 14.48 & 2.43 & 5.68 & 11.68 & 12.18 \\
\hline & & SR3 & 9.89 & 6.90 & 5.17 & 3.57 & 9.25 & 8.08 \\
\hline & & R3 & 9.79 & 7.66 & 4.89 & 3.39 & 8.20 & 8.16 \\
\hline
\end{tabular}

The seismic demand of axial load, shear, and moment for walls E-CM, V-AH and U-SO (Figure 5), considering the four modeling assumptions (SR1, SR2, SR3 and R3) are shown in Figure 13. The figure shows the seismic demands at the instant of maximum roof displacement for the same seismic cases considered in Figure 7 (i.e. one ground motion for each wall).

The comparison of the axial load demands for the three walls shows that, the maximum loads of model SR2 with increased slab stiffness are on average $26 \%$ larger than those of model SR1. This supports the idea that the slab stiffness exerts a tangible influence in the prediction of seismic axial load demands of RC walls. When gross sections are considered (model R3 and SR3), the seismic axial loads increase on average by 2.2 times for the model SR3 and 2.4 times for the model R3, compared to the model SR1. Therefore, the stiffness of structural members plays a major role in the prediction of the axial load demands. Finally, a comparison between the models SR3 and R3 shows that the diaphragm stiffness has a notable influence on the axial load demand only for the wall $\mathrm{V}-\mathrm{AH}$, since the maximum axial load for the model $\mathrm{R} 3$ is $10,560 \mathrm{kN}$ while for the model SR3 is 7,884 kN. For the other two walls, the assumed in-plane stiffness of the diaphragm in model R3 has a negligible influence on the axial load demands of this wall. 


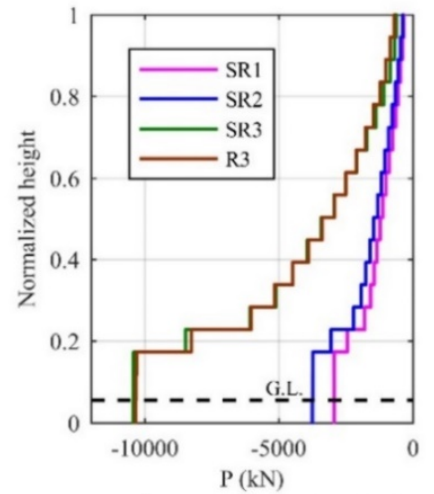

a) Axial load, E-CM



d) Axial load, V-AH

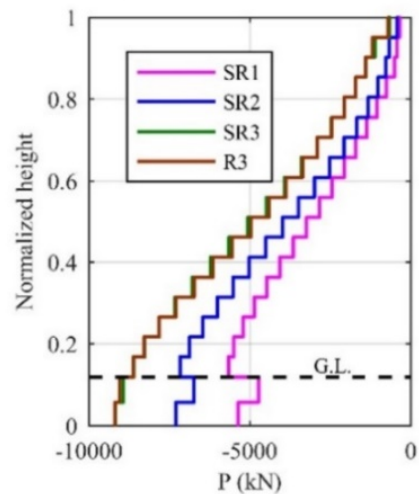

g) Axial load, U-SO

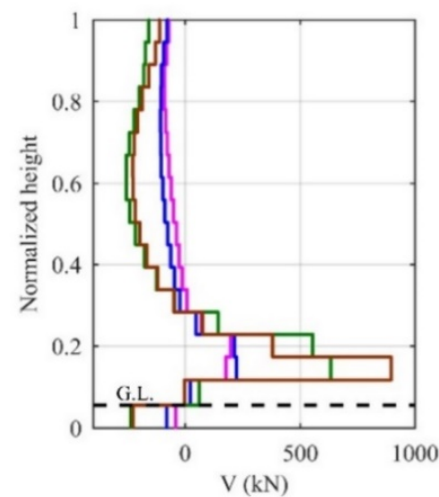

b) Shear, E-CM

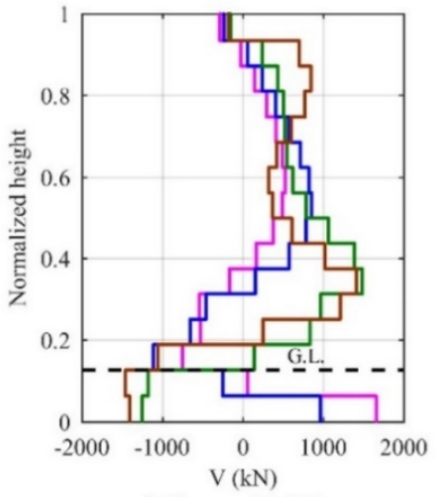

e) Shear, V-AH

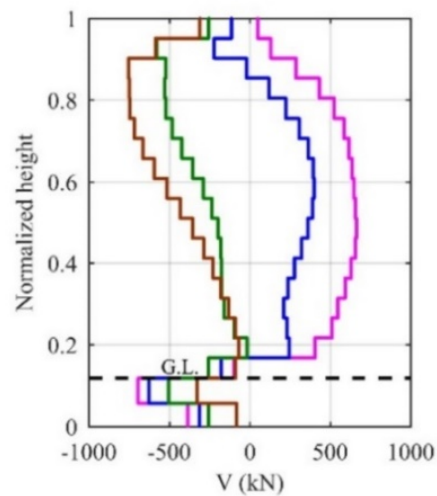

h) Shear, U-SO

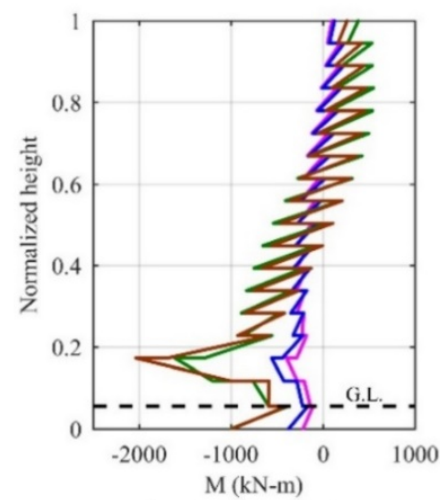

c) Moment, E-CM

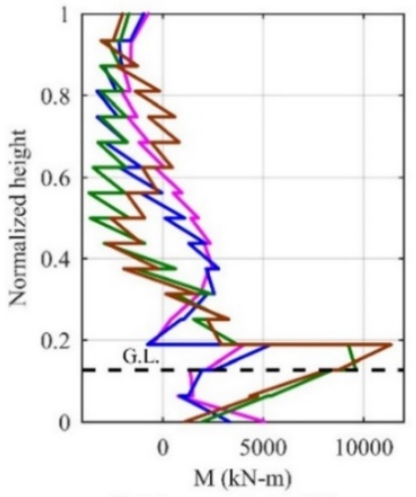

f) Moment, $\mathrm{V}-\mathrm{AH}$

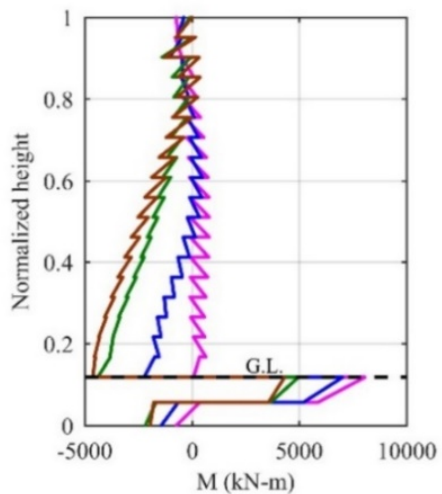

i) Moment, U-SO

Figure 13 Seismic demand for four modeling assumptions: a) P of E-CM wall; b) V of E-CM wall; c) M of E-CM wall; d) P of V-AH wall; e) V of V-AH wall; f) M of V-AH wall; g) P of U-SO wall; h) V of U-SO wall and i) M of U-SO wall. (G.L. correspond to the ground level).

The seismic shear demand is also influenced by the modeling assumption. Comparing the SR1 and SR2 model, Figure 13 shows that the slab stiffness has a small effect on the estimation of the shear demand for the wall E-CM, whereas it has a larger effect on the estimation for the walls $\mathrm{V}-\mathrm{AH}$ and U-SO. When gross sections are considered (R3 and SR3), the shear demands for all three walls are significantly different than those of the model SR1. Therefore, the assumed stiffness of structural members exerts and important influence on the prediction of the shear demand. In particular, for the wall $\mathrm{V}-\mathrm{AH}$, the back-stay effect and sign changes are more evident in the models SR3 and R3 than in the model SR1. When models with gross stiffness (R3 and SR3) are compared, Figure 13 shows that the diaphragm stiffness exerts an influence both in the magnitude and the shape of the shear diagram. In particular, it is observed that for the wall V-AH the shear diagram of the model R3 has one sign change whereas that of the model SR3 has three sign changes. Additionally, for the wall E-CM, the maximum predicted shear with the model SR3 is $635 \mathrm{kN}$, while that with the model R3 is $897 \mathrm{kN}$.

The moment diagrams in Figure 13 show that when less cracked slabs are assumed (model SR2), the shapes and maximum predicted values vary slightly, except for the wall U-SO, where differences are observed between $10 \%$ and $30 \%$ of the building height. The bending moment values and shapes predicted by models SR3 and R3, are significantly different 
than those predicted by the model SR1. Particularly for the wall V-AH, the diagram has a double curvature that is more evident for the model SR3 than for the model SR1. This suggests that the stiffness of structural members has an important effect on the predicted bending moment profiles. The comparison between the bending moments predicted with the model SR3 and R3 shows that the diaphragm stiffness has an important influence both in the sign changes as well as in the magnitudes of the moment. The former can be appreciated for the wall $\mathrm{V}-\mathrm{AH}$, where a double curvature profile is observed for model SR3 and a triple curvature for model R3. The latter can be observed in the U-SO wall, whose maximum moments occur at same story, but their magnitudes are 4,953 kN-m and 4,308 kN-m, for the models R3 and SR3, respectively.

Based on the presented results of the three walls, it is concluded that the effect of the elements' stiffness has a significant influence on the predicted values of the axial load, shear and moment in RC walls. The observed trend suggests that when cracked sections are considered (models SR1 and SR2), the predicted seismic demands are lower than those when gross sections are used (models SR3 and R3). The results also support that the assumed in-plane diaphragm stiffness influences the behavior of the shear and moment along the wall's height, yet with an unclear trend.

\section{CONCLUSIONS}

This paper investigates the contribution of coupling elements to the seismic demands of axial load, shear and moment of walls in complex RC buildings with three-dimensional interaction of structural elements. Additionally, the effects of using different modeling assumptions on these demands are evaluated. The seismic demands of the reference model (SR1) were obtained from elastic analyses using reduced moment of inertia to account for the cracking and inelastic action near or beyond the yield level. The obtained results allow drawing the following conclusions:

1. The seismic axial load of the analyzed RC walls was mostly attributed to the slabs, which contributed more than $90 \%$ in six out of the eight analyzed walls, for both in compression and tension cases. For the other two walls, the contribution of beams to the seismic axial load was $57 \%$ and $69 \%$, exceeding the contributions of the slabs. For the wall connected to adjacent walls (U-SO), such adjacent walls contributed larger than beams to the seismic axial load.

2. Large seismic ALRs, up to 0.83 , were predicted for the studied walls with design-level ground motions. Additionally, for five out of the eight analyzed walls the seismic ALRs exceeded the ALRs obtained from dead load. Therefore, total tensile forces are expected to develop at the first story of such walls when seismic forces induce tension forces.

3. Large variability of the seismic axial load, shear and moment demand was predicted when using different ground motions scaled at the same intensity. The simultaneous application of both ground motions influenced this variability.

4. The moment profiles obtained for the studied walls are significantly different than common profiles obtained for cantilever walls, which are commonly assumed by design codes (e.g. ACl 318). The obtained profiles also different than profiles reported for coupled walls through coupling beams. This result suggests that common design assumption to relate the roof displacement with the curvature demand in walls may be inadequate for the studied walls.

5. The assumed stiffness of structural elements showed a significant influence on the prediction of the seismic axial load demands of the studied walls. Increasing the slab stiffness from $0.25 \mathrm{lg}$ to $0.40 \mathrm{lg}$ increased the seismic axial load by $26 \%$ on average. When gross sections are considered, the seismic axial load increased on average by 2.2 times when compared to the reference model with effective stiffness (SR1). Additionally, the use of gross sections also exerts a significate influence on the shape and magnitude of shear and moment diagrams.

6. The assumed in-plane stiffness of the diaphragm showed negligible effect on the predicted seismic demand of axial load, shear and moment. However, in one of the studied walls, it exerted an influence both in the magnitude and the shape of the shear and moment profiles.

Due to the significant influence showed by the stiffness of structural elements on the estimation of the seismic demands of axial load, shear and moment of the studied walls of the selected buildings, future research considering the nonlinear behavior of the structural elements is mandatory. In such model, the nonlinear modeling of the slab is found to be critical in order to better understand the influce of the slab over the seismic response of RC buildings and walls. 


\section{ACKNOWLEDGEMENTS}

This research has been funded by Grants ANID/Doctorado Nacional/2015, ANID/Fondecyt/1171062 and ANID/FONDAP/15110017. The authors are also grateful for the support of Rosita Jünemann, Orlando Arroyo and José Gallardo.

Author's contributions: Conceptualization, L Ramos and MA Hube; Methodology, L Ramos and MA Hube; Investigation L Ramos and MA Hube, Writing - original draft, L Ramos; Writing - review \& editing, MA Hube; Resources, MA Hube; Supervision, MA Hube.

Editor: Marcílio Alves.

\section{REFERENCES}

Aksogan, O., Turkozer C.D., Emsen, E., Resatoglu, R., (2014). Dynamic analysis of non-planar coupled shear walls with stiffening beams using Continuous Connection Method. Thin-Walled Structures 82: 95-104.

Alarcón, C., Hube, M.A., de la Llera, J.C., (2014). Influence of axial load in the seismic behavior of RC walls unconfined wall boundaries. Engineering Structures 73: 13-23.

Alarcón, C., Hube, M.A., Jünemann, R, de la Llera, J.C., (2015). Characteristics and displacement capacity of reinforced concrete walls in damaged buildings during 2010 Chile earthquake. Bulletin of Earthquake Engineering 13 (4): 1119-1139.

$\mathrm{ACl}$ - American Concrete Institute (1995), Building code requirements for structural concrete and commentary. (ACl 318-95), Farmington Hills, MI.

$\mathrm{ACl}$ - American Concrete Institute (2014), Building code requirements for structural concrete and commentary. (ACl 318-14), Farmington Hills, MI.

Bertero, V.V., Atkan, A.E., Charney, F., Sause, R., (1985). Earthquake simulator tests and associated experiments, analytical and correlation studies of one-fifth scale model. Earthquake effects on reinforced concrete structures, U.S. - Japan research. ACl Publication SP-84: 375-424.

Boroschek, R.L., Contreras, V., Kwak, D.Y., Stewart, J.P., (2012). Strong ground motion attributes of the 2010 Mw 8.8 Maule, Chile, earthquake. Earthquake Spectra 28(S1): S19-S38.

CSN - National Seismological Center (2019). University of Chile, Faculty of Physical Sciences and Mathematics: http://www.sismologia.cl/. Accessed march 2019.

Chacón, M.F., de la Llera, J.C., Hube, M.A., Marques, J., Lemnitzer, A., (2017). Epistemic uncertainty in the seismic response of RC free-plan buildings. Engineering Structures 141: 687-702.

ETABS - Computers and Structures (2010), Inc (Version V9)

Englekirk, R.E., (2003). Seismic design of reinforced and precast concrete buildings. 848 pages. ISBN: 978-0-471-08122-7. John Wiley \& Sons.

Fischinger, M., Kante, P., Isakovic, T., (2017). Shake-table response of a coupled RC wall with thin T-shaped piers. Journal of Structural Engineering, DOI: 10.1061/(ASCE)ST.1943-541X.0001718.

Fox, M., Sullivan, T., Beyer, K., (2014a): Comparison of force-based and displacement-based design approaches for RC coupled walls in New Zealand. Bulletin of the New Zealand Society for Earthquake Engineering, 47 (EPFL-ARTICLE-202735), 190-205.

Fox, M., Sullivan, T., Beyer, K., (2014b): Capacity design of coupled RC walls. Journal of Earthquake Engineering, 18 (5), $735-$ 758.

Habibullah, A., (1992): ETABS users' manual. Computers and Structures, Inc., Berkeley, California, USA.

Harries, K.A, Moulton, J.D, Clemson, R.L., (2004): Parametric study of coupled wall behavior-implications for the design of coupling beams. Journal of Structural Engineering, 130 (3), 480-488. 
INN - National Institute of Standardization (2008): Reinforced concrete - design and calculation requierement, NCh430 Of.2008. Santiago, Chile (in spanish).

INN - National Institute of Standardization (1996): Earthquake resistant design of buildings, NCh433 Of.1996. Santiago, Chile (in spanish).

Jünemann, R., de La Llera, J.C., Hube, M.A., Cifuentes, L.A., Kausel, E., (2015). A statistical analysis of reinforced concrete wall buildings damaged during the 2010, Chile earthquake. Engineering Structures 82: 168-185.

Jünemann, R., de la Llera, J.C., Hube, M.A., Vásquez, J., Chacón, M.F., (2016). Study of the damage of reinforced concrete shear walls during the 2010, Chile earthquake. Earthquake Engineering and Structural Dynamic 45(10): 1621-1641.

Lehman, D.E., Turgeon, J.A., Birely, C., Hart, C.R., Marley, K.P., Kuchma, D.A., Lowes, N., (2013). Seismic behavior of a modern concrete coupled wall. Journal of Structural Engineering 139(8): 1371-1381.

Lepage, A., (1998). Nonlinear drift of multistory RC structures during earthquakes. In Proceedings of Sixth National Conference on Earthquake Engineering, Seattle, WA.

Lu, Y., Panagiotou, M., (2016). Three-dimensional beam-truss model for reinforced concrete walls and slabs - part 2: modeling approach and validation for slabs and coupled walls. Earthquake Engineering \& Structural Dynamics 45(11): $1707-1724$.

MINVU - Ministry of Housing and Urbanism (2011), DS61: Earthquake resistant design of buildings, replacing D.S. N 1172010. Official Diary, 13 December 2011 (in Spanish).

Moehle, J.P., (1992). Displacement-based design of RC structures subjected to earthquakes, Earthquake Spectra 8 (3): $403-$ 428. DOI: $10.1193 / 1.1585688$.

Moehle, J.P., (2015). Seismic design of reinforced concrete buildings. 760 pages. ISBN: 978-0-07-183945-7. McGraw-Hill Education.

Panagiotou, M., Restrepo, J.I., Conte, J.P., (2011): Shake table test of a 7-story full scale reinforced concrete wall building slice, phase I: rectangular wall. Journal of Structural Engineering, 137 (6), 691-704.

Panagiotou, M., Kim, G., Barbosa, A., Restrepo, J.I., (2009). Response verification of a reinforced concrete bearing wall building located in an area of high seismic hazard. Rep. prepared for the Portland Cement Association.

Panagiotou, M., and Restrepo, J.I., (2009). Dual-plastic hinge design concept for reducing higher mode effects on high-rise cantilever wall buildings. Earthquake Engineering and Structural Dynamics 38(2): 1359-1380.

Paulay, T., (1986). The design of ductile reinforced concrete structural walls for earthquake resistance. Earthquake Spectra 2 (4): 783-823.

Pennucci, D., Sullivan, T.J., Calvi, G.M., (2015). Inelastic higher-mode response in reinforced concrete wall structures. Earthquake Spectra 31(3): 1493-1514.

Pugh, J.S., Lowes, L.N., Lehman, D.E., (2017): Accurate methods for elastic seismic demand analysis of reinforced concrete walled buildings. Journal of Structural Engineering, DOI:10.1061/(ASCE)ST.1943-541X.0001669.

Priestley, M.J., and Amaris, A., (2003). Dynamic amplification of seismic moments and shear forces in cantilever walls. Proceedings, Fib Symposium, Concrete Structures in Seismic Regions, Athens, Greece.

ONEMI - National Emergency Office (2019). Ministry of interior and public security and University of Chile, Department of Civil Engineering. Earthquakes of Chile 2010. http:// terremotos.ing.uchile.cl/2010. Accessed march 2019.

Wallace, J.W., Massone, L.M., Bonelli, P., Dragovich, J., Lagos, R., Lüders, C., Moehle J., (2012). Damage and implications for seismic design of RC structural wall buildings. Earthquake Spectra 28(S1): S281-S299.

Westenenk, B., de la Llera, J.C., Besa, J.J., Jünemann, R., Moehle, J., Lüders, C., Inaudi, J.A., Elwood, K., Hwang, S.J., (2012). Response of reinforced concrete buildings in Concepción during the Maule earthquake. Earthquake Spectra 28 (S1): S257S280.

Westenenk, B., de la Llera, J.C., Jünemann, R., Hube, M.A., Besa, J.J., Lüders, C., Inaudi, J.A, Riddell. R., Jordán, R., (2013). Analysis and interpretation of the seismic response of RC buildings in Concepción during the February 27, 2010 Chile Earthquake. Bulletin of Earthquake Engineering 11(1): 69-91. 


\section{SUPPLEMENTAL DATA}

A database with the ground motion set proposed in this paper is available in this link or through the corresponding. 